\title{
BMJ Open Socioeconomic inequalities in caries experience, care level and dental attendance in primary school children in Belgium: a cross-sectional survey
}

\author{
Martijn J Lambert, ${ }^{1}$ Jacques S N Vanobbergen, ${ }^{1}$ Luc C Martens, ${ }^{2}$ \\ Luc M J De Visschere ${ }^{1}$
}

To cite: Lambert MJ, Vanobbergen JSN, Martens LC, et al. Socioeconomic inequalities in caries experience, care level and dental attendance in primary school children in Belgium: a crosssectional survey. BMJ Open 2017;7:e015042. doi:10.1136/ bmjopen-2016-015042

- Prepublication history for this paper is available online. To view these files please visit the journal online (http://dx.doi org/10.1136/bmjopen-2016015042).

Received 16 December 2016 Revised 1 June 2017 Accepted 2 June 2017

\section{CrossMark}

${ }^{1}$ Department of Community Dentistry and Oral Public Health, Dental School, Ghent University, Ghent, Belgium

${ }^{2}$ Department of Paediatric Dentistry and Special Care, Paecomedis Research Cluster, Dental School, Ghent University, Ghent, Belgium

Correspondence to

Mr Martijn J Lambert; lambert_ martijn@hotmail.com

\section{ABSTRACT}

Objectives Oral health inequality in children is a widespread and well-documented problem in oral healthcare. However, objective and reliable methods to determine these inequalities in all oral health aspects, including both dental attendance and oral health, are rather scarce.

Aims To explore oral health inequalities and to assess the impact of socioeconomic factors on oral health, oral health behaviour and dental compliance of primary school children.

Methods Data collection was executed in 2014 within a sample of 2216 children in 105 primary schools in Flanders, by means of an oral examination and a validated questionnaire. Intermutual Agency database was consulted to objectively determine individuals' social state and frequency of utilisation of oral healthcare services. Underprivileged children were compared with more fortunate children for their mean DMFt, DMFs, plaque index, care index (C, restorative index (RI), treatment index (TI), knowledge and attitude. Differences in proportions for dichotomous variables (Rl100\%, $\mathrm{Tl} 100 \%$ and being a regular dental attender) were analysed. The present study was approved by the Ethics Committee of the University Hospital Ghent (2010/061). All parents signed an informed consent form prior to data collection. All schools received information about the study protocol and agreed to participate. Children requiring dental treatment or periodic recall were referred to the local dentist. Results Underprivileged children had higher D1MFT ( $95 \%$ Cl 0.87 to 1.36 ), D3MT ( $95 \% \mathrm{Cl} 0.30$ to 0.64 ), plaque scores $(95 \% \mathrm{Cl} 0.12$ to 0.23$)$ and lower care level $(p<0.02)$. In the low-income group, $78.4 \%$ was caries-free, compared with $88.4 \%$ for the other children. Half of the low-income children could be considered as regular dental attenders, while $12.6 \%$ did not have any dental visit during a 5 -year period.

Conclusion Oral health, oral hygiene, oral healthcare level and dental attendance patterns are negatively affected by children's social class, leading to oral health inequalities in Belgian primary school children.

\section{INTRODUCTION}

\section{Background}

Although dental caries is largely preventable, it is a major public health problem,

\section{Strengths and limitations of this study}

- Large and random selected sample of children in the last year of primary school.

- Oral health and oral health behaviour are linked to social security databases on oral healthcare utilisation for a 5-year period. This objective information is seldom available in international literature on healthcare utilisation, but is far more reliable than a self-administered questionnaire, avoiding bias.

- Sample only includes Belgian subjects.

- The design of the study does not allow us to identify specific causes for inequalities in oral health and dental non-attendance, only associations.

- Since Glimlachen.be is a 4-year longitudinal programme visiting schools, most of the subjects will have received previous dental screenings before the present data collection. These screenings might have positively influenced the oral health and oral health behaviour of all children, resulting in an underestimation of oral health-related problems. However, this influence should be equal for both compared groups.

since untreated tooth decay remains by far the most common chronic disease worldwide. ${ }^{1}$ International data on childhood caries epidemiology confirm that dental caries remains a 'significant and consequential disease of childhood', being increasingly localised in a subgroup of high-risk children, both in developing and developed countries. $^{2}$

Dental caries is a multifactorial disease. Consumption of sugary substances and poor oral health practices largely affect the occurrence of tooth decay. Literature provides powerful evidence that dental caries is positively correlated to sugar intake $^{3}$ and adversely correlated to tooth brushing with a fluoridated toothpaste. ${ }^{4}$ However, all dietary and behavioural 
determinants of caries are influenced by people's social context, resulting in worsened oral health outcomes in underprivileged groups. Socioeconomic inequalities in preschool children have already been reported nationally and internationally. Van den Branden highlights the occurrence of early childhood caries in preschool children (3-5 years old) and provides some evidence that a social gradient in early childhood caries can be suggested. ${ }^{5}$ This confirms results from earlier national reports and is consistent with international literature. ${ }^{2}{ }^{6-8}$ For the Belgian situation however, the mentioned national reports only include preschool children. Recent data from children attending school are scarce, but certainly needed..$^{9}$

The occurrence of dental caries and other oral diseases is not the only domain in which inequalities appear. Use of oral healthcare facilities and regular preventive dental check-up are also affected by social variables. In adulthood, it is clear that dental non-attenders rank significantly more often at the lower end of the socioeconomic scale. ${ }^{10}$ Regarding the financial aspect of oral healthcare in Belgium, a fee-for-service payment method is used, combined with a compulsory health insurance. In this system, a patient pays the entire dental visit cost to the dentist at first hand, in order to recover at second hand the biggest part of this sum from his health insurance agency. To reduce inequalities in (oral) health, some national government initiatives have been implemented. Underprivileged individuals can be entitled to an increased allowance for healthcare interventions when the family income is low. In case of excessive medical costs, people can also have access to the mechanism known as the 'Maximum Bill', calculating a cost limit for medical care for every individual. The higher the family income, the higher the cost limit. When medical costs exceed this limit, they will be entirely and automatically reimbursed. Furthermore, a full coverage of regular treatment costs for all children under the age of 18 is guaranteed, provided that the dentist acceded to the convention between the national health insurance agency and dental professional organisations. For 2015-2016 period, $62.64 \%$ of Belgian dentists partially or completely took part in this convention.

\section{Objectives}

Objective data on children's dental non-attendance and health consumption are scarce in Belgium and worldwide. By involving the Intermutual Agency (IMA) national database data on utilisation of (oral) healthcare services, this article provides objective information on oral health consumption and dental attendance.

In this study, the authors aimed to explore existing oral health inequalities and to assess the impact of socioeconomic factors on oral health, oral health behaviour and dental compliance of primary school children.

\section{MATERIALS AND METHODS}

\section{Study design, settings and population}

The present survey fits into the context of Glimlachen. be, a prospective 4-year longitudinal oral health promotion programme, visiting primary schools in Flanders (Belgium) with a mobile dental unit. It is conducted by dentists of the Flemish Dental Association under the authority of the National Institute for Health and Disability Insurance .

The present cross-sectional study reports on the oral health condition of children in the last year of primary school, recruited in all schools in Flanders within the three educational networks (GO publicly run under the authority of the Flemish Community (15\%); OGO publicly funded and publicly run by local authorities or provincial authorities (15\%); VGO publicly funded and privately run by private non-profit-making organisations, mainly catholic schools $(70 \%)$ ).

Data were collected in 2014 from a representative sample of 2216 primary school children in 105 different schools in Flanders. The total study population is estimated to be about 68000 children in 2340 schools. Schools were randomly selected, based on a two-step stratification. In the first step, a stratified randomisation was executed at school-level, based on three strata: number of pupils, region and educational network. In the next step, randomisation occurred at the individual level. There was an oversampling of $2 \%$ for schools with assistance from special education for disabled children or children with learning or educational difficulties. The sample size was determined based on a confidence level of $95 \%$ and a margin of error of $2.5 \%$. There were several sample size estimations, depending on the variability of the different outcome variables. The authors decided to include as many children as practically possible, based on the availability of three mobile dental units and the number of school days.

\section{Data collection}

In all participants, oral health condition was recorded by visual inspection with a mobile dental unit in school premises by 44 well-trained and calibrated dentist-examiners. All examiners were blinded to the socioeconomic status of the children they examined. Calibration was undertaken to avoid bias, using a series of full-mouth photographs simulating the clinical examination of patients, set up in a PowerPoint presentation. Intraclass correlation coefficient for all examiners was 0.86 with a $95 \%$ CI of 0.82 to 0.90 . General kappa score was 0.72 .

Individual children have been examined for several oral health parameters. DMFt was used as outcome variable to count the number of decayed (D), missing (M) and filled $(\mathrm{F})$ teeth. Caries detection was based on the International Caries Detection and Assessment System, using six subcategories of caries going from first visible change in enamel (score 1 ) to extensive cavity with visible dentin possibly reaching the pulp (score 6 ). Both caries at D1 level (score $>0$ : early enamel lesions and decay 
into dentine) and D3 level (score $\geq 4$ : obvious decay into dentine, excluding early lesions restricted to the enamel) were taken into account. The level of provided care has been approached through the restorative index $(\mathrm{RI}=(\mathrm{Ft})$ $\left.(\mathrm{D} 3+\mathrm{Ft}))^{*} 100\right)$, with Ft standing for 'filled teeth', care index $((\mathrm{Ft} /(\mathrm{D} 3+\mathrm{M}+\mathrm{Ft})) * 100)$ and treatment index $(\mathrm{TI}=((\mathrm{M}+\mathrm{Ft}) /(\mathrm{D} 3+\mathrm{M}+\mathrm{Ft})) * 100)$, all ranging from $0 \%$ to $100 \%$. These indices can only be calculated for those children having a DMFt score $>0$. For the other children (DMFt $=0$ ), it is mathematically impossible to calculate RI, CI and TI, since the formula should request to divide by ' 0 '. RI and TI were also dichotomised to divide subjects into two groups: children without untreated caries $(\mathrm{RI}=100 \%, \mathrm{TI}=100 \%)$ and children with untreated caries (RI $<100 \%, \mathrm{TI}<100 \%)$.

Clinical amount of dental plaque was measured using the Plaque Index of Sillness and Löe. ${ }^{11}$ This index calculates the mean buccal surface plaque score of six reference teeth on a scale from 0 (no plaque) to 3 (visible plaque on more than one-third of the buccal surface).

Both knowledge and attitude were assessed by a validated and reliable questionnaire, answered by the children. A higher score out of 10 correlates to more knowledge and a better attitude. An expert panel tested the content validity of the items, after which the questionnaire was pretested in a class of 25 primary school children (convenience sample) on two different time points (test-retest). Internal consistency was analysed by means of the Cronbach's alpha, resulting in a score of 0.75 , which fits into the required interval of $0.70<$ Cronbach's alpha $<0.90$.

To explore the impact of social environment on oral health and oral health related behaviour, knowledge and attitude, a summary measure was used to characterise the deprivation level. All parameters have been analysed in children eligible for the 'Maximum Bill' for at least 1 year between 2009 and 2013, compared with those who cannot take part of this system (dichotomous explanatory variable). The Maximum Bill measure is automatically assigned to individuals in order to reimburse medical costs exceeding a certain limit, based on income levels. Accordingly, those who benefit from it correspond to underprivileged individuals. Those without can be considered as middle-income and high-income subjects. The combined questionnaire and oral health examination data were supplemented with the IMA national database data on utilisation of (oral) healthcare services, in order to trace individuals who can make use of the Maximum Bill and to obtain information on participants' frequency of utilisation of oral healthcare services. This includes all attested dental treatments and regular preventive dental check-ups over a period from 2009 to 2013. By consensus, participants are considered as regular dental attenders if IMA database reported at least one dental visit in three different years over a 4-year period, excluding urgency treatments. Subsequently, a dichotomous variable has been created to distinguish regular dental attenders from non-regular dental attenders.

\section{Data analysis}

Data analysis was carried out in the IBM SPSS Statistics V.22.0 (SPSS). Independent sample t-test was used to compare underprivileged and more fortunate individuals for their mean DMFt, DMFs, plaque index, Care Index, RI, TI, knowledge and attitude scores. A parametrical test was used, based on the central limit theorem. Differences in proportions for dichotomous variables (RI100\%, TI100\% and being a regular dental attender) have been compared in crosstabs, using a $\chi^{2}$ statistical test. Alpha was set at $<0.05$.

The approach used to deal with incomplete records and so to avoid bias, was to compare the proportion of children eligible for the 'Maximum Bill' in both responders and non-responders (no clinical data available), by using the $\chi^{2}$ statistical test. This social parameter could be determined for all children by using the national registration number of the child and the IMA database.

\section{Ethical aspects}

The present study was approved by the Ethics Committee of the University Hospital Ghent (2010/061). All parents signed an informed consent form prior to data collection. All schools received information about the study protocol and agreed to participate. Children requiring dental treatment or periodic recall were referred to the local dentist.

\section{RESULTS}

Sample consisted of 2216 Flemish primary school children with a mean age of 11.25 years (SD 0.68). Data analysis was performed in $88.2 \% \quad(n=1954)$. Incomplete records were due to failure to obtain consent and child's absence from school on the day of examination. From these 1954 children, 1771 completed the questionnaire. Comparing the social status of responders and non-responders, the proportion of children eligible for the 'Maximum Bill' was equal for both groups ( $\chi^{2}$ test; $\left.\mathrm{p}=0.4\right)$.

More than $19 \%(n=374)$ of the children made use of the Maximum Bill. Being part of this subgroup significantly affected oral health and oral health behaviour, as demonstrated in table 1. Underprivileged children showed worse outcomes for all explanatory variables. They had a higher plaque index and higher DMFt and DMFs scores, both at D1 and D3 level. Overall care level was significantly lower, resulting in a lower care index, TI and RI. Both knowledge and attitude scores were slightly but significantly lower in low-income children.

Regarding the proportion of participants being completely treated for caries, underprivileged children again differ from their more fortunate counterparts. According to table 2, 78.4\% of the low-income children were caries-free $(\mathrm{DMFt}=0)$, compared with $88.4 \%$ for the high-income group. From those having a DMFt $>0,55.3 \%$ of the Maximum Bill group children were found to have a $100 \%$ TI against $65.8 \%$ for children of higher social class. The same trend appeared when comparing the $100 \%$ RI, 
Table 1 Oral health and oral health behaviour between children from low-income (utilising the 'Maximum Bill') and middle-tohigh-income families

\begin{tabular}{|c|c|c|c|c|c|c|c|}
\hline & Maximum Bill & $\mathbf{N}$ & Mean & SD & Mean diff. & $95 \% \mathrm{Cl}$ & p Value \\
\hline \multirow{2}{*}{$\begin{array}{l}\text { Mean plaque index } \\
\text { (missing=1) }\end{array}$} & No & 1602 & 0.41 & 0.48 & -0.17 & $(-0.23$ to -0.12$)$ & $<0.001$ \\
\hline & Yes & 351 & 0.59 & 0.58 & & & \\
\hline \multirow{2}{*}{$\begin{array}{l}\text { DMFt (D1-level) } \\
\text { (missing=1) }\end{array}$} & No & 1601 & 1.68 & 2.05 & -1.12 & $(-1.36$ to -0.87$)$ & $<0.001$ \\
\hline & Yes & 352 & 2.79 & 2.43 & & & \\
\hline \multirow{2}{*}{$\begin{array}{l}\text { DMFt (D3-level) } \\
\text { (missing=2) }\end{array}$} & No & 1600 & 0.78 & 1.42 & -0.47 & $(-0.64$ to -0.30$)$ & $<0.001$ \\
\hline & Yes & 352 & 1.25 & 1.68 & & & \\
\hline \multirow{2}{*}{$\begin{array}{l}\text { DMFs (D1-level) } \\
\text { (missing=0) }\end{array}$} & No & 1602 & 2,30 & 3.25 & -1.72 & $(-2.11$ to -1.32$)$ & $<0.001$ \\
\hline & Yes & 352 & 4,02 & 4.07 & & & \\
\hline \multirow{2}{*}{$\begin{array}{l}\text { DMFs (D3-level) } \\
\text { (missing=0) }\end{array}$} & No & 1602 & 1,18 & 2.51 & -0.83 & $(-1.13$ to -0.52$)$ & $<0.001$ \\
\hline & Yes & 352 & 2,00 & 3.16 & & & \\
\hline \multirow{2}{*}{$\begin{array}{l}\text { Care index* } \\
(\text { missing }=0)\end{array}$} & No & 544 & 70.33 & 42.14 & 11.87 & (4.47 to 19.27 ) & $<0.001$ \\
\hline & Yes & 170 & 58.46 & 45.17 & & & \\
\hline \multirow{2}{*}{$\begin{array}{l}\text { Treatment index* } \\
\text { (missing }=0)\end{array}$} & No & 544 & 73.13 & 40.83 & 8.34 & (1.18 to 15.51$)$ & 0.02 \\
\hline & Yes & 170 & 64.79 & 43.75 & & & \\
\hline \multirow{2}{*}{$\begin{array}{l}\text { Restorative index } \\
(\text { missing=0) }\end{array}$} & No & 537 & 72.18 & 41.57 & 9.96 & (2.54 to 17.38 ) & 0.01 \\
\hline & Yes & 164 & 62.22 & 44.79 & & & \\
\hline \multirow{2}{*}{$\begin{array}{l}\text { Knowledge } \\
\text { (missing=183) }\end{array}$} & No & 1483 & 7.58 & 2.12 & 0.80 & (0.52 to 1.07$)$ & $<0.001$ \\
\hline & Yes & 288 & 6.78 & 2.49 & & & \\
\hline \multirow{2}{*}{$\begin{array}{l}\text { Attitude } \\
\text { (missing=183) }\end{array}$} & No & 1482 & 8.37 & 1.32 & 0.27 & (0.10 to 0.44$)$ & 0.002 \\
\hline & Yes & 289 & 8.10 & 1.44 & & & \\
\hline
\end{tabular}

*Of those having DMFt $>0$.

resulting in strongly significant differences. Half of the low-income children $(50.3 \%)$ could be considered as regular dental attenders for the period between 2009 and 2013, while $12.6 \%$ did not have any dental visit during this 5-year period. Middle-income and high-income children visited the dentist on a more regular basis, resulting in a $77.7 \%$ rate for regular dental attendance. Only $3.4 \%$ of these children did not report any dental visit. All of these differences proved to be statistically significant.

\section{DISCUSSION}

Oral health inequalities are clearly visible within the present sample of primary school children. Since 2216 subjects were randomly selected in 105 different primary schools in Flanders, results can be extrapolated to the entire Flemish region.

All included oral health parameters were strongly significantly affected by participants' social class. Caries experience, by means of DMFt and DMFs, proved to be higher in underprivileged groups and oral hygiene (plaque index) and the level of care seemed to depend on families' social context. This level of care was assessed by means of the RI, care index and TI. These indices could only be calculated for children having a DMFt $>0$. This was mathematically declared in the methodological section, by explaining that it is impossible to divide by ' 0 ', which

Table 2 Dental compliance and caries-free proportions between children from low-income (using the 'Maximum Bill') and middle-to-high-income families

\begin{tabular}{|c|c|c|c|}
\hline & Maximum Bill & & \\
\hline Variable & No & Yes & p Value \\
\hline Treatment index $(\mathrm{Tl}=100 \%)^{*}$ & $65.8 \%(n=358)$ & $55.3 \%(n=94)$ & 0.01 \\
\hline Restorative index $(\mathrm{Rl}=100 \%)^{*}$ & $65.4 \%(n=351)$ & $53.7 \%(n=88)$ & 0.008 \\
\hline Regular dental attender $†$ & $77.7 \%(n=1344)$ & $50.3 \%(n=188)$ & $<0.001$ \\
\hline No dental visit between 2009 and 2013 & $3.4 \%(n=59)$ & $12.6 \%(n=47)$ & $<0.001$ \\
\hline Caries-free proportion & $88.4 \%(n=1414)$ & $78.4 \%(n=276)$ & $<0.001$ \\
\hline
\end{tabular}

*Dichotomous explanatory variable.

†At least one dental visit in three different years over a 4-year period, excluding urgency treatments. 
would be the case for those having a $\mathrm{DMF} t=0$. Also clinically, this would be irrelevant, because the indices aim to calculate the proportion of the decayed teeth which have been restored or extracted. If there is no caries experience at all $(\mathrm{DMFt}=0)$, these indices are not applicable.

An arithmetic gap of 11.87, 8.34 and 9.96 emerges when comparing Care index, TI and RI for middle/ high-income and low-income children, in disadvantage of the latter group. The three indices do not all have the same meaning. Restorative index $(\mathrm{RI}=(\mathrm{Ft} /(\mathrm{D} 3+\mathrm{Ft}))$ *100) does not consider the missing teeth, because there can be doubts whether teeth were removed due to caries or due to other factors (trauma, periodontal infection). Care index $\left(\mathrm{CI}=(\mathrm{Ft} /(\mathrm{D} 3+\mathrm{M}+\mathrm{Ft}))^{*} 100\right)$ partially involves the missing teeth, but the index does not consider a tooth extraction as a 'solution', but as part of the problem. Children are literally 'missing' a tooth, so tooth extraction it is seen as a 'lost chance'. On the other hand, treatment Index $(\mathrm{TI}=((\mathrm{M}+\mathrm{Ft}) /(\mathrm{D} 3+\mathrm{M}+\mathrm{Ft})) * 100)$ proposes tooth extraction as part of the solution, because it removes a (potential) focus of infection. It gives the same value to fillings and extractions. None of these indices can be considered as 'all-embracing', so it is good to compare them. When two subgroups differ significantly in RI, but not in TI, this means that one of the groups received more tooth extractions, which can be relevant to explore the severity of the disease and the way of treating it. The present findings suggest that the low-income children had more teeth being extracted, although it is hard to determine the clinical relevance of a $1 \%$ difference between TI and RI.

Statistical analysis clearly demonstrates underprivileged children to visit less frequently the dental practitioner. One out of eight low-income children (12.6\%) did not see a dentist one single time during the 5 years prior to data collection. This dental absenteeism is almost four times higher in underprivileged groups compared with the more fortunate subgroups.

The present Flemish/Belgian results on oral health inequalities are not a unique phenomenon, but are in accordance with global findings. International literature is overloaded with recent evidence demonstrating social inequalities in oral health. A systematic review by Schwendicke et al shows that low social class is associated with an increased risk of dental caries, especially in more developed countries. ${ }^{12}$ Childhood financial hardship has a main impact on individuals oral health during childhood and in later life. Poulton $e t a l^{3}$ revealed that low childhood socioeconomic status (SES) contributes to increased adult levels of caries and periodontal disease, even after adjusting for adult SES. Listl $e t a l^{14}$ confirmed these findings, showing the long-term adverse effects of financial problems in childhood on oral health in middle and later adulthood.

Today's persistence of social inequalities, both in Flanders and in the entire world, is food for thought. From the most negative point of view, one could state that all previous oral health promotion campaigns, health promoting schools and governmental interventions simply failed to close the social gap in oral health. Unfortunately, the present cross-sectional survey is not able to uncover a specific reason for this failure. What needs to be considered and further investigated is the key role played by the family and environmental context in children's dental adherence. It is clear that 12-year-old children cannot be taken fully responsible for being a dental non-attender. A systematic review of Freire de Castilho ${ }^{15}$ reveals that parental oral health habits affects children's oral health. For this reason, the authors of this review state that oral health promotion programmes need to put emphasis on the entire family context, concerning their lifestyle and oral health behaviour.

Regarding the financial aspect, basic dental costs are completely reimbursed in Belgium for all children under the age of 18 without distinction, so in fact differences in utilisation of healthcare services for financial reasons are not expected. However, in most dental practices, the often high dental fee needs to be paid first by the client 'out of pocket', to get it reimbursed by the health insurance agency afterwards. Third party payment, in which the health insurance agency pays the dental fee directly to the dental practitioner instead of the client, is allowed for all minors, but not well established. Further, $37.36 \%$ of the Belgian dentists did not take part in the fee convention, bearing a risk of potentially increased dental costs. The authors cannot draw conclusions in this respect, but want to express the need to determine the principal cause(s) of oral health inequalities. The specific provider payment method can be one of the factors, but probably not the only one. Regarding knowledge and attitude of the children in this study, there are statistically significant differences between both social subgroups. However, a mean difference of 0.27 in attitude (on a score out of 10) might be of little clinical relevance to explain the existing inequalities. For children's knowledge, this gap is bigger, with a mean difference of 0.80 in knowledge scores. Differences in knowledge and health literacy, attitude and lifestyle need further investigated for children and for the parents.

Although oral health inequalities have always existed and are still remaining, society cannot simply acquiesce in its existence. Dental caries is largely preventable, but still remains the most prevalent chronic disease worldwide, mainly affecting high-risk subgroups. ${ }^{16}$ Dental treatment is expensive, absorbing a considerable part of overall healthcare budget. ${ }^{17}$ Focussing on prevention and tackling oral health inequalities improve individuals' oral health and quality of life and help in reducing governmental costs. Watt et $a l^{18}$ call in the 'London Charter on Oral Health Inequalities' for a more upstream public health approach, targeting the deeper social, political and economic causes of oral health inequalities. They advocate new multidisciplinary preventive strategies at local, regional, national and international levels, based on a common risk factor approach. Quoting the authors, 'collaborative efforts among researchers, policy 
makers, public health practitioners, clinical teams, and the public are urgently required'. So, decisions on oral health promotion and tackling oral health inequalities should not exclusively be made by policy-makers, but should also involve dentists and intermediate partner organisations.

The 'Marmot Review'" provides a guidance to assess the social gradient in health, by introducing the method of 'proportionate universalism'. Interventions do not need to focus only on the most disadvantaged individuals and should be universal and contain a scale and intensity in accordance with subgroups' level of disadvantage.

The authors understand that the oral health status of Belgian children might be of less relevance in international literature. Although, this survey describes a very relevant theme: social inequalities in health. Off course, many other authors did research on this topic. However, the present study certainly has an added value. What pleads in favour is the large sample of children with the same age, but more important, the objective and reliable link that was provided between children's oral health, their social status and their oral healthcare utilisation. Oral health was investigated by calibrated and blinded dentists. Afterwards, these findings were linked to people's social class, not by interviewing the patients or their parents, but by exploring data of the national health institute. In this way, dental examiners were blinded, and people could not 'hide' their social status for the researchers. Furthermore, the same database revealed the most reliable information on oral healthcare utilisation. Mostly, dental attendance is assessed by means of a questionnaire, inevitably leading to bias. In this survey, every single dental visit of a child could be linked to its corresponding record. It is obvious that this kind of survey requires a strict procedure, to ensure children's medical data and privacy. Because of the sensitive character of the information, studies with the same setting are very rare. A short literature search on Pubmed with the following string 'Oral Health' [Mesh] AND 'health care utilization' [All Fields]' resulted in only seven hits. Two Nigerian surveys reported on almost the same subject, but both of them used a self-administered questionnaire..$^{20} 21$

The authors also have to report some limitations of the study. Although oral health figures can be comparable with other western countries, the present sample only included Belgian subjects. Further, the cross-sectional study design does not allow the authors to identify specific causes for inequalities in oral health and dental non-attendance, only associations.

Since Glimlachen.be is a 4-year longitudinal programme visiting schools, most of the subjects will have received previous dental screenings before the present data collection. These screenings might have positively influenced the oral health and oral health behaviour of all children, resulting in an underestimation of oral health-related problems. However, this influence should be equal for both compared groups.

\section{CONCLUSION}

Oral health inequalities are an undeniable reality in primary school children in Flanders/Belgium. Oral health, oral hygiene, oral healthcare level and dental attendance patterns are negatively affected by children's social class.

Acknowledgements The authors thank the Flemish Dental Association (VVT), the dentist examiners and dental assistants and the school for their collaboration.

Contributors All authors declare to have had substantial contributions to the conception and design of the work, to have drafted and revised the work for important intellectual content. All authors gave final approval of the version to be published and agreement to be accountable for all aspects of the work. The corresponding author MJL's task was to analyze data and write the present article. JSNV, LMJDV and LCM are the PhD supervisors of MJL. They are all participating in the 'Glimlachen.be' project from its very beginning. In that way, they could provide essential information on data collection procedure and other methodological aspects of the present study. Their expertise was indispensable to realize this publication.

Funding The research presented in this report is part of the 'Glimlachen.be' project (www.glimlachen.be), commissioned and financed by the 'Insurance Committee for Health Care' of the 'Belgian National Institute for Health and Disability Insurance'.

Competing interests None declared.

Patient consent Detail has been removed from this case description/these case descriptions to ensure anonymity. The editors and reviewers have seen the detailed information available and are satisfied that the information backs up the case the authors are making.

Ethics approval Ethics Committee of the University Hospital Ghent (2010/061) reference number B67020108008.

Provenance and peer review Not commissioned; externally peer reviewed.

Data sharing statement Patient level data or full data set and statistical code book are available from the corresponding author on request.

Open Access This is an Open Access article distributed in accordance with the Creative Commons Attribution Non Commercial (CC BY-NC 4.0) license, which permits others to distribute, remix, adapt, build upon this work non-commercially, and license their derivative works on different terms, provided the original work is properly cited and the use is non-commercial. See: http://creativecommons.org/ licenses/by-nc/4.0/

(C) Article author(s) (or their employer(s) unless otherwise stated in the text of the article) 2017. All rights reserved. No commercial use is permitted unless otherwise expressly granted.

\section{REFERENCES}

1. Marcenes W, Kassebaum NJ, Bernabé E, et al. Global burden of oral conditions in 1990-2010: a systematic analysis. J Dent Res 2013;92:592-7.

2. Edelstein BL. Pediatric caries worldwide: implications for oral hygiene products. Compend Contin Educ Dent 2005;26(5 Suppl 1):4-9.

3. Sugars MP. And Dental Caries: evidence for setting a recommended threshold for Intake. Adv Nutr 2016;15;7:149-56.

4. Chaves SC, Vieira-da-Silva LM. [Anticaries effectiveness of fluoride toothpaste: a meta-analysis]. Rev Saude Publica 2002;36:598-606.

5. Van den Branden S, Van den Broucke S, Leroy R, et al. Oral health and oral health-related behaviour in preschool children: evidence for a social gradient. Eur J Pediatr 2013;172:231-7.

6. Declerck D, Leroy R, Martens L, et al. Factors associated with prevalence and severity of caries experience in preschool children. Community Dent Oral Epidemiol 2008;36:168-78.

7. Do LG. Distribution of caries in children: variations between and within populations. J Dent Res 2012;91:536-43.

8. Willems S, Vanobbergen J, Martens L, et al. The Independent Impact of Household- and Neighborhood-based social determinants on Early Childhood Caries. Fam Community Health 2005;28:168-75.

9. Vanobberge JN, Martens LC, Lesaffre E, et al. Parental occupational status related to dental caries experience in 7-year-old children in Flanders (Belgium). Community Dent Health 2001;18:256-62. 
10. Listl S, Moeller J, Manski R. A multi-country comparison of reasons for dental non-attendance. Eur J Oral Sci 2014;122:62-9.

11. Löe H. The Gingival Index, the Plaque Index and the Retention Index Systems. J Periodontol 1967:38:610-6.

12. Schwendicke F, Dörfer CE, Schlattmann P, et al. Socioeconomic inequality and caries: a systematic review and meta-analysis. J Dent Res 2015;94:10-18.

13. Poulton R, Caspi A, Milne BJ, et al. Association between children's experience of socioeconomic disadvantage and adult health: a lifecourse study. The Lancet 2002;360:1640-5.

14. Listl S, Watt RG, Tsakos G. Early life conditions, adverse life events, and chewing ability at middle and later adulthood. Am J Public Health 2014:104:e55-e61.

15. Castilho AR, Mialhe FL, Barbosa Tde S, et al. Influence of family environment on children's oral health: a systematic review. J Pediatr 2013;89:116-23.
16. Kassebaum NJ, Bernabé E, Dahiya M, et al. Global burden of untreated caries: a systematic review and metaregression. J Dent Res 2015;94:650-8.

17. Listl S, Galloway J, Mossey PA, et al. Global economic impact of dental diseases. J Dent Res 2015;94:1355-61.

18. Watt RG, Heilmann A, Listl S, et al. London Charter on Oral Health Inequalities. J Dent Res 2016;95:245-7.

19. Marmot M. 2010. The Marmot Review Final Report: Fair Society, Healthy Lives. London: University College London. http://www. instituteofhealthequity.org/projects/fair-society-healthy-lives-themarmot-review

20. Onyejaka NK, Folayan MO, Folaranmi N. Barriers and facilitators of dental service utilization by children aged 8 to 11 years in Enugu State, Nigeria. BMC Health Serv Res 2016;16:93 1341-6.

21. Ajayi DM, Arigbede AO. Barriers to oral health care utilization in Ibadan, South West Nigeria. Afr Health Sci 2012;12:507-13. 